\title{
Comparison of European, African, Asian, and Other/ Mixed Race American Children for the Association Between Household Income and Perceived Discrimination
}

\author{
Shervin Assari ${ }^{1,2^{*}}$, Ali Ayoubian ${ }^{3}$, Cleopatra H. Caldwell ${ }^{4,5}$ \\ ${ }^{1}$ Department of Urban Public Health, Charles R. Drew University of Medicine and Science, Los Angeles, CA 90059, USA \\ ${ }^{2}$ Department of Family Medicine, Charles R. Drew University of Medicine and Science, Los Angeles, CA 90059, USA \\ ${ }^{3}$ National Center for Health Insurance Research, Iran Health Insurance Organization, Tehran, Iran \\ ${ }^{4}$ Department of Health Behavior and Health Education, University of Michigan, University of Michigan, Ann Arbor, MI 48109, USA \\ ${ }^{5}$ Center for Research on Ethnicity, Culture, and Health, University of Michigan, University of Michigan, Ann Arbor, MI 48109, USA
}

Corresponding Author: Shervin Assari, MD, MPH, Associate Professor, Department of Family Medicine, Charles R. Drew University of Medicine and Science, Los Angeles, USA. Tel: +1-734-2320445, Fax: +1-734-6158739, Email: assari@umich.edu

Received August 2, 2020; Accepted November 11, 2020; Online Published November 21, 2020

\begin{abstract}
Introduction: Perceived discrimination is one of the reasons behind ethnic health disparities. However, less is known about racial and ethnic groups differ in social determinants of discrimination. This study aimed to compare the association between household income and perceived discrimination among American children of different racial groups.

Methods: The Adolescent Brain Cognitive Development (ABCD) study, a national longitudinal study, followed 4383 children 9-10 years old who were either European American, African American, Asian American, or mixed/other race for one year. We compared racial groups for the association between baseline household income and perceived discrimination at the end of one year follow up. We used ANOVA and linear regression for data analysis. The outcome was perceived discrimination. The predictor was household income. Covariates were age, gender, and parental marital status. The moderator was race.

Results: In the total sample, high household income was associated with less perceived discrimination. There was an interaction between race and household income, suggesting a difference in the association between household income and perceived discrimination between African American and European American children. The inverse association between household income and perceived discrimination was weaker for African American than European American children.

Conclusion: High-income African American children are not well protected against perceived discrimination. High exposure to perceived discrimination may explain the worse expected health and development of middle-class African American children. As discrimination is a major social determinant of health, the results have considerable implications for public health policy.

Keywords: Socioeconomic Status, Income, Education, Racism, Discrimination, Health
\end{abstract}

Citation: Assari S, Ayoubian A, Caldwell CH. Comparison of European, African, Asian, and other/mixed race American children for the association between household income and perceived discrimination. Int J Travel Med Glob Health. 2021;9(1):31-38. doi:10.34172/ijtmgh.2021.06.

\section{Introduction}

Socioeconomic status (SES) indicators such as household income protect most populations from poor health. ${ }^{1}$ The Minorities' Diminishing Returns (MDRs) phenomenon, ${ }^{2,3}$ however, refers to smaller returns of SES for racial minorities relative to European Americans. ${ }^{4}$ These MDRs are robust as they are observed in all age groups, from childhood to older adulthood. ${ }^{4}$ As a result of these MDRs, we observe increased risk of depression in middle-class minority individuals. ${ }^{5}$

Researchers such as Oliver and Shapiro ${ }^{6}$ and Hamilton and Darity ${ }^{7}$ have described a substantial wealth gap between racial and ethnic minority and European American families. Based on this wealth gap, life conditions of individuals with similar education and income levels differ for European and minority populations. They have also described the African Americans' tax, defined as the hidden psychological cost associated with being a middle-class African American individual in the US. ${ }^{8}$ We observed reduced effects of household income for racial minorities due to institutional and structural racism as well as interpersonal discrimination. However, there is less knowledge available about the role of income on perceived discrimination across various racial groups. We know even less about the experiences of perceived discrimination among children from high income minority backgrounds. ${ }^{9}$

Copyright $\odot 2021$ The Author(s). This is an open-access article distributed under the terms of the Creative Commons Attribution License (http:// creativecommons.org/licenses/by/4.0), which permits unrestricted use, distribution, and reproduction in any medium, provided the original work is properly cited. 
Perceived discrimination has been mentioned as a plausible mechanism that can explain diminished returns of high income for African American families. ${ }^{4,9}$ Multiple review papers have linked perceived discrimination to multiple undesirable physical and mental health outcomes. ${ }^{10,11}$ Research has shown that the social patterning of perceived discrimination is different for African American and European American individuals. ${ }^{12-14}$ For African American families, high income levels may paradoxically increase rather than decrease perceived discrimination. ${ }^{9}$ This seems to be in part because high-income African American families have increased contact with European Americans, as they migrate to neighborhoods and work with mainly European American coworkers. ${ }^{12}$ For European Americans, however, high SES reduces discrimination, ${ }^{15}$ a pattern opposite from what we see in African Americans. ${ }^{9,13}$

Although theoretically speaking, perceived discrimination is an ideal explanation for the observed MDRs, very few studies have specifically compared European American and African American individuals for differences in the associations between SES and perceived discrimination. In a study, Colen and colleagues, ${ }^{13}$ analyzed data from the Longitudinal Survey of Youth (NLSY) and showed that for European Americans, income gain over time was associated with reduced exposure to perceived discrimination. Upwardly mobile African American people, however, reported more, not less, perceived discrimination, when compared to socioeconomically stable African Americans. ${ }^{13}$ While there are other studies showing that high SES may increase perceived discrimination among African American people,${ }^{14}$ those studies have been limited to African American individuals only ${ }^{16}$. These studies do not provide information on differential association between SES and perceived discrimination between European American and African American people.

This study used a national sample of American children to compare racial groups for the association between household income and perceived discrimination. In this study, we are interested in having a better understanding of how race and income jointly impact the perceived discrimination of American children. Our Hypothesis 1 was an inverse association between household income and perceived discrimination overall. Our Hypothesis 2 was a weaker inverse association between household income and perceived discrimination for African American than European American children.

\section{Methods}

Design and Settings

This longitudinal study is a secondary analysis of existing data. One year follow-up data of the Adolescent Brain Cognitive Development (ABCD) study were used. The ABCD is a landmark brain development study in the United States. Here we briefly review some key aspects of the study.

\section{Participants and Sampling}

Participants of the ABCD study were children between ages 9 and 11. Children in the ABCD study were recruited from multiple cities across states. Participants were enrolled from 21 sites overall. The primary source of recruitment for the
ABCD sample was US school systems. A total number of 4383 participants entered this analysis. Our analysis's eligibility included valid data on race, ethnicity, demographics, parental education, parental marital status, household income, and children's whole-brain cortical surface area. Participants were included in this analysis regardless of their race, ethnicity, or twin status.

\section{Study Variables}

The study variables included baseline household income (independent variables), child race (moderator), children's age, sex, ethnicity, parental education, parental marital status (confounders), and perceived discrimination (dependent variable) at the end of one year follow up.

\section{Dependent Variable}

\section{Perceived Discrimination}

Perceived discrimination was measured using seven items, at the end of one year follow up. One example item was "How often do the following people treat you unfairly or negatively because of your ethnic background?" Items ranged from 1 to 5 , with 1 referring to $=$ almost never and 5 referring to very often. Participants were allowed to say they don't know or refuse to answer. The total score was an average of the items, ranging from 1 to 5 , with a higher score indicating more discrimination.

\section{Independent Variable \\ Household Income}

Household income was a 3-level nominal variable, and measured at baseline: less than 50 thousand dollars (reference category), 50-100 thousand dollars, and more than 100 thousand dollars.

\section{Confounders}

Age, sex, ethnicity, parental marital status, and parental education were the confounding variables. Parents reported the child's age, which was calculated as months between the date of birth and the study's date. Sex of the child was a dichotomous variable that was coded 0 for males and 1 for females. The self-identification of the parents measured child ethnicity. Ethnicity was a dichotomous variable and coded 1 for Latino and 0 for non-Latino (reference category) families. Parental marital status was also a dichotomous variable, selfreported by the parent interviewed, and coded 1 vs. 0 for married and unmarried. Participants' parental education was an ordinal variable: less than high school (reference category), high school, college, graduate+ school.

\section{Moderator}

Race

Race was self-identified by the parents. Race was a categorical variable: African American, Asian American, Other/Mixed, and European American (reference category).

\section{Data Analysis}

We used the DEAP for data analysis. Provided by the Data Analysis and Informatics Core of ABCD, the Data Analysis 
and Exploration Portal (DEAP) uses R and provides a userfriendly online platform for multivariable analysis of the ABCD data. The DEAP platform is available here https:// deap.nimhda.org, and ABCD data was downloaded from here: https://nda.nih.gov/abcd. For our univariate analysis, we reported Mean [standard deviation (SD)] and frequency (\%) depending on the variable type. We also performed ANOVA for all our variables. For each parameter in the model, unstandardized regression coefficients (b), SE, and $P$ value were reported for each model. A $P$ value equal to or less than 0.05 was considered statistically significant.

ANOVA and Linear regression were used for data analysis. Regression in DEAP is based on mixed-effect models, given participants are tested to families, and families are nested to sites. The primary outcome was the children's perceived discrimination. The independent variable was household income. Age, sex, family marital status, ethnicity, and parental education were the covariates. As such, in all our models, we controlled for the effects of families as sites. Our multi-level modeling approach is shown in Table S1 (see Supplementary file 1). These models are run in a nested fashion, and small variations distinguish them at each step. Model 1 tested the additive effects of household income and race, with the same covariates, without interaction terms. Model 2 tested the interaction between household income and race. We checked a wide range of assumptions, including lack of collinearity between predictors, normal distribution of our outcome, the distribution of errors for our model as well as the association between observed and theoretical quantiles of our model
Figure S1 (see Supplementary file 1).

\section{Results}

Descriptive Statistics

This study included 4383 participants. As shown in Table 1, African American children had the lowest levels of parental education and household income, and European American children had the highest levels of household income. African American children reported the highest levels of perceived discrimination, and European American children reported the lowest levels of discrimination.

\section{Pooled Sample}

In Table 2, we summarize the results of a mixed-effects regression with perceived discrimination as the outcome. High household income was associated with lower perceived discrimination in the pooled sample (Figure 1).

Table 2 also shows the results of Model 2 that added interaction terms between race and household income. This model suggests the association between household income and perceived discrimination is significantly different between European American and African American adults (Figure 2).

\section{Discussion}

In a national sample of 9-10-year-old children, two major results were observed. First, high household income was associated with lower levels of perceived discrimination overall. Second, race altered how high income is associated

Table 1. Demographics Descriptive Data in the Pooled Sample by Race

\begin{tabular}{|c|c|c|c|c|c|c|}
\hline Level & & White & Black & Asian & Other/Mixed & \\
\hline \multirow[t]{2}{*}{$N$} & 4383 & 3211 & 400 & 104 & 668 & $P$ Value \\
\hline & n (\%) & n (\%) & n (\%) & n (\%) & n (\%) & \\
\hline \multicolumn{7}{|l|}{ Sex } \\
\hline Female & $2100(47.9)$ & $1506(46.9)$ & $195(48.8)$ & $55(52.9)$ & $344(51.5)$ & 0.117 \\
\hline Male & $2283(52.1)$ & $1705(53.1)$ & $205(51.2)$ & $49(47.1)$ & $324(48.5)$ & \\
\hline \multicolumn{7}{|l|}{ Parental education } \\
\hline$<\mathrm{HS}$ diploma & $113(2.6)$ & $62(1.9)$ & $14(3.5)$ & $0(0.0)$ & $37(5.5)$ & $<0.001$ \\
\hline HS diploma/GED & $259(5.9)$ & $129(4.0)$ & $71(17.8)$ & $0(0.0)$ & $59(8.8)$ & \\
\hline Some college & $1051(24.0)$ & $665(20.7)$ & $157(39.2)$ & $9(8.7)$ & $220(32.9)$ & \\
\hline Bachelor & $1249(28.5)$ & $998(31.1)$ & $74(18.5)$ & $22(21.2)$ & $155(23.2)$ & \\
\hline Post graduate degree & $1711(39.0)$ & $1357(42.3)$ & $84(21.0)$ & $73(70.2)$ & $197(29.5)$ & \\
\hline \multicolumn{7}{|l|}{ Household income } \\
\hline$<50 \mathrm{~K}$ & $1036(23.6)$ & $556(17.3)$ & $215(53.8)$ & $10(9.6)$ & $255(38.2)$ & $<0.001$ \\
\hline$\geq 100 \mathrm{~K}$ & $2005(45.7)$ & $1646(51.3)$ & $66(16.5)$ & $69(66.3)$ & $224(33.5)$ & \\
\hline$\geq 50 K \&<100 K$ & $1342(30.6)$ & 1009 (31.4) & $119(29.8)$ & $25(24.0)$ & $189(28.3)$ & \\
\hline \multicolumn{7}{|l|}{ Parents married } \\
\hline No & $1167(26.6)$ & $655(20.4)$ & $242(60.5)$ & $14(13.5)$ & $256(38.3)$ & $<0.001$ \\
\hline Yes & $3216(73.4)$ & $2556(79.6)$ & $158(39.5)$ & $90(86.5)$ & $412(61.7)$ & \\
\hline \multicolumn{7}{|l|}{ Hispanic } \\
\hline No & $3614(82.5)$ & $2716(84.6)$ & $380(95.0)$ & $96(92.3)$ & $422(63.2)$ & $<0.001$ \\
\hline \multirow[t]{2}{*}{ Yes } & $769(17.5)$ & $495(15.4)$ & $20(5.0)$ & $8(7.7)$ & $246(36.8)$ & \\
\hline & Mean (SD) & Mean (SD) & Mean (SD) & Mean (SD) & Mean (SD) & \\
\hline Age (months) & $132.04(7.60)$ & $132.13(7.61)$ & $131.74(7.26)$ & $132.79(7.72)$ & $131.64(7.75)$ & 0.271 \\
\hline Perceived discrimination (Log) & $0.12(0.22)$ & $0.10(0.19)$ & $0.24(0.33)$ & $0.09(0.18)$ & $0.15(0.24)$ & $<0.001$ \\
\hline
\end{tabular}


Table 2. Linear Regression on the Association Between Household Income and Perceived Discrimination in the Overall Sample

\begin{tabular}{lccc}
\hline & B & SE & $\boldsymbol{P}$ \\
\hline Model 1 & & & \\
Household Income $[\geq 50 \mathrm{~K} \&<100 \mathrm{~K}]$ & $-0.03^{* * *}$ & 0.01 & 0.001 \\
Household Income $[\geq 100 \mathrm{~K}]$ & $-0.04^{* * *}$ & 0.01 & $<0.001$ \\
Model 2 & & & \\
Household Income $[\geq 50 \mathrm{~K} \&<100 \mathrm{~K}]$ & $-0.04^{* *}$ & 0.01 & 0.003 \\
Household Income $[\geq 100 \mathrm{~K}]$ & $-0.05^{* * *}$ & 0.01 & $<0.001$ \\
Race $[$ Black] & $0.10^{* * *}$ & 0.02 & $<0.001$ \\
Race $[$ Asian] & -0.04 & 0.07 & 0.507 \\
Race $[$ Other/Mixed $]$ & 0.03 & 0.02 & 0.075 \\
Household Income $[\geq 50 \mathrm{~K} \&<100 \mathrm{~K}] \times$ Black & -0.02 & 0.03 & 0.488 \\
Household Income $[\geq 100 \mathrm{~K}] \times$ Black & $0.09^{* *}$ & 0.03 & 0.006 \\
Household Income $[\geq 50 \mathrm{~K} \&<100 \mathrm{~K}] \times$ Asian & 0.06 & 0.08 & 0.482 \\
Household Income $[\geq 100 \mathrm{~K}] \times$ Asian & 0.08 & 0.07 & 0.275 \\
Household Income $[\geq 50 \mathrm{~K} \&<100 \mathrm{~K}] \times$ Other/Mixed & 0.01 & 0.02 & 0.657 \\
Household Income $[\geq 100 \mathrm{~K}] \times$ Other/Mixed & 0.00 & 0.02 & 0.896 \\
\hline$* * P<0.01 * * * P<0.001 *$ & & &
\end{tabular}

with perceived discrimination: While high-income European American children report low discrimination, high-income African American children report high levels of perceived discrimination.

Our results relate to several studies. Colen and colleagues ${ }^{13}$ showed that for European American families, income gain reduces exposure to perceived discrimination. Upward mobility, however, may increase exposure to discrimination for African American families. ${ }^{13}$ In one study, higher income European Americans self-reported improved mental health, while African American individuals across all income levels self-reported poor mental health. ${ }^{17}$ Another study demonstrated that upward/downward educational mobility was associated with an increase in stressful life events among European Americans. Meanwhile, African American individuals reported high amounts of stressful life events, regardless of their social mobility status. ${ }^{18}$ The independent variable in our study, however, was income rather than upward mobility. While they are connected, our results should not be interpreted as correlates of social mobility.

As our results show, high SES does not mean less perceived discrimination for African American children. For African Americans, high income fails to protect the family against racial discrimination ${ }^{9}$. This is in addition to the effect of race on perceived discrimination that occurs regardless of social position. Thus, race-based stress, also called discrimination, is higher in most educated African Americans. This provides a plausible explanation for MDRs of education in African American people. ${ }^{9}$ Studies have demonstrated that racerelated stress is particularly detrimental to the mental health of African American individuals. ${ }^{19}$

High levels of perceived discrimination in high income African Americans means health risk is spilled over across all SES levels in African American families. For African Americans, individuals with high SES report more discrimination; for European Americans, individuals with low SES report high levels of discrimination. ${ }^{15}$ Some have suggested that perceived discrimination is mainly a function of race/ethnicity; thus, human capital accumulation or materialistic resources would not protect them against discrimination. ${ }^{9,15}$ Prejudice is deeply embedded in the fabric of US society. Racist ideologies, implicit bias, prejudice, and stereotypes affect various aspects of African American individuals' lives across settings and institutions. ${ }^{20}$

This is not the first-time research has shown diminished returns of income for African Americans. Shapiro and Oliver have discussed the African American and European American wealth gap ${ }^{6}$, a pattern called African American tax. $^{8}$ Research shows that African American individuals often gain fewer tangible outcomes than European American Americans across income levels. Darity and Hamilton have also documented an extensive wealth gap between European Americans and African Americans. ${ }^{7}$ As salaries are lower for African Americans compared to European Americans, African American parents need to work more than European American parents to secure the same income. ${ }^{6,8}$ Some of these inequalities may be due to labor market discrimination and differing school quality between African American and European American individuals. As such, rather than being a

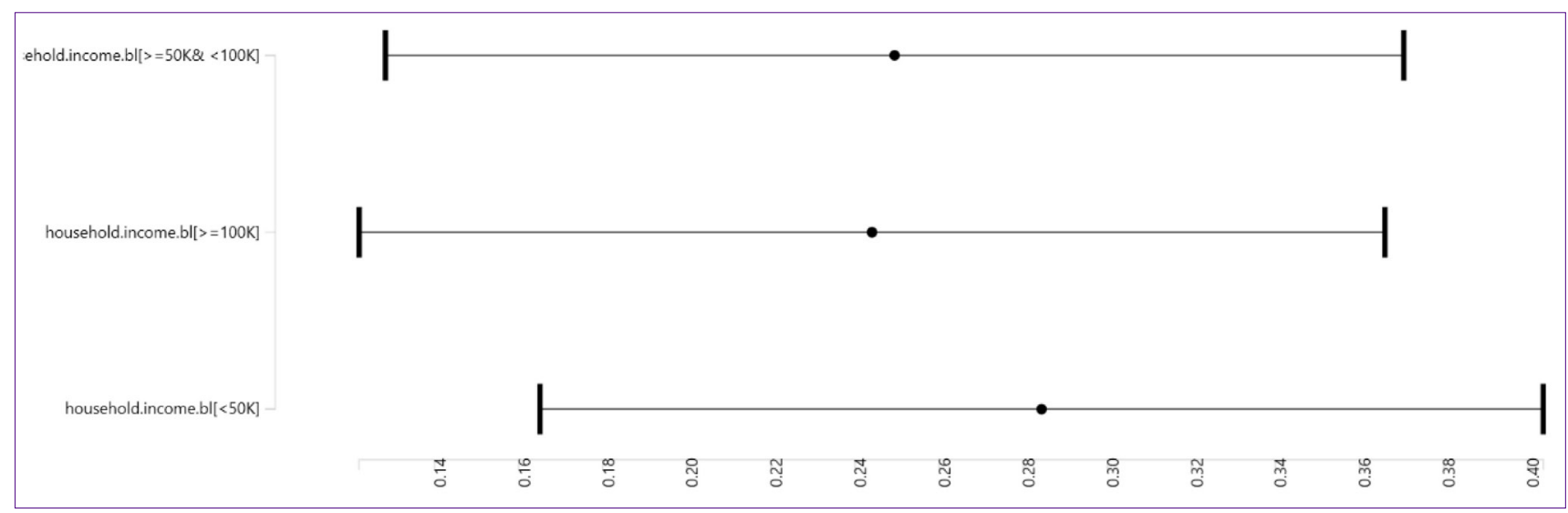

Figure 1. Association Between Household Income and Perceived Discrimination Overall. 

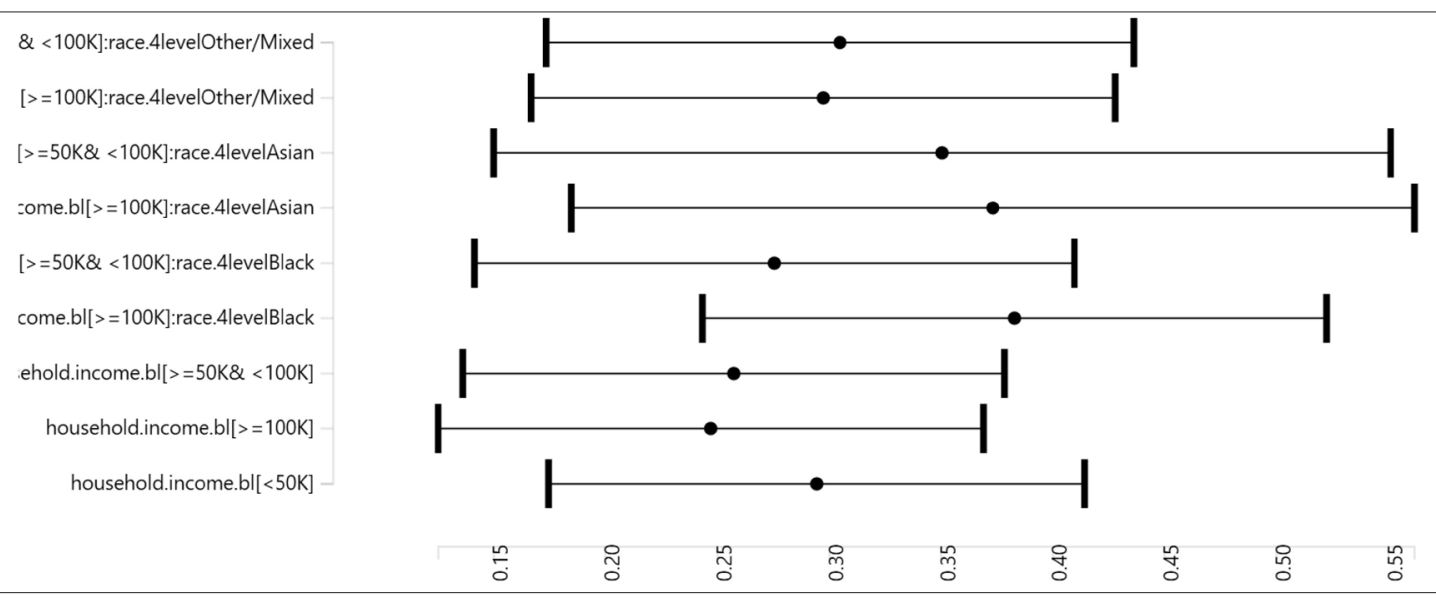

Figure 2. Association Between Household Income and Perceived Discrimination by Race.

solution to inequalities, or an equalizer, income and education have become a source of inequality in the US. ${ }^{21}$ Some of these observed differences are due to how society gives more value to European American ancestry. ${ }^{22}$

Many scholars such as Williams, ${ }^{23}$ Farmer and Ferraro, ${ }^{3}$ Navarro, ${ }^{24}$ Wilson et $\mathrm{al}^{25}$ and Oliver and Shapiro ${ }^{6,8}$ have provided evidence suggesting that racial gaps are largest at the highest SES levels. Navarro has argued that it is "race and class" rather than "race or class" that shapes racial inequalities. ${ }^{24}$ Thus, the problem for African Americans is not merely a lack of materialistic resources or poverty for African Americans but also the added burden of racism. Racism is associated with race-based discrimination for African Americans across all SES levels. ${ }^{26,27}$ Wilson et $\mathrm{a}^{25}$ showed that European Americans' purchasing power is better enhanced by income than African Americans'.

High perceived discrimination of children from highincome African American families may give us a potential and plausible explanation for why African American children and adults receive less physical and mental health benefits from their SES resourcesn. ${ }^{28}$ For African Americans, discrimination is experienced across the entire SES spectrum. African American families cannot escape racism and discrimination via upward social mobility. Social stratification, structural inequalities, prejudice all limit the daily lives of African American families. Racism and discrimination defer the American dream for African American individuals. ${ }^{29}$

The results are important, considering that discrimination has been connected to increased rates of depression, suicide, poor health care use, distress, and drug use. ${ }^{30}$ Discrimination during adolescence is a predictor of poor mental health two decades later. ${ }^{31}$ However, it is not only class and race but the intersectional of race with class, nativity, age, and sex/gender that exposes a child or an adolescent to discrimination. ${ }^{32,33}$ Similarly, it is not only race but the intersection of race and sex/gender that shapes vulnerability to perceived discrimination. ${ }^{34-36}$ Proximity to Whites may be why high SES African Americans report high levels of perceived discrimination. ${ }^{35-38}$

In the current study, we used ABCD data and showed high discrimination in high SES African American children. In a number of recent studies that used the very same data sets, ${ }^{39-}$ ${ }^{50}$ high SES has shown to generate fewer outcomes across emotional, behavioral, and even brain imaging results for African American children compared to European American children. ${ }^{39-50}$ In other terms, our paper provides an explanation for why we observe MDRs across outcomes ${ }^{39-51}$ in the ABCD study.

\section{Next Step for Research}

Future research on this topic should go beyond the effects of income across racial groups by studying groups based on the intersections of gender/sex, class, age, nativity, etc. African American males experience high levels of discrimination due to sexualized or gendered racism..$^{52}$ In the US, police killings, stop and frisk, and the war on drugs have specifically targeted African American males. Between-group relations are more challenging for males than females. Upward social mobility is also least likely for African American males. ${ }^{53}$ Thus, members of racial and ethnic groups experience more discrimination when they are male. ${ }^{52}$ Future research may compare African American males and females for predictors and outcomes of discrimination. ${ }^{54}$

\section{Limitations}

To list our limitations, first, this study was a short-term follow up study with single time point of SES and perceived discrimination. Therefore, our results do not imply causation but the association between household income and perceived discrimination. This is important because household income and perceived discrimination may have bidirectional associations. Second, this study only investigated one SES indicator. Wealth, education, homeownership, neighborhood income, and employment could generate different results. We also did not study types and sources of discrimination. Discrimination may be due to race, class, gender, nationality, physical health, or age. Third, this study could not cover some confounders, such as depression or health. Finally, this study investigated the statistical rather than clinical significance of discrimination and immigration status. More research is 
needed on various effects of discrimination on population health.

\section{Conclusion}

Race alters the link between household income and perceived discrimination. That is, the inverse association between household income and perceived discrimination is weaker for African American than European American individuals. Future research should investigate whether high levels of perceived discrimination explains worse-than-expected outcomes in African American children from high-income families (i.e. MDRs).

\section{Authors' Contributions}

Conceptualization: SA and AA. Formal analysis: SA. Writing-original draft: SA. Writing-review and editing: $\mathrm{SA}$ and $\mathrm{AA}$ and $\mathrm{CH}$. All authors have read and agreed to the published version of the manuscript.

\section{Conflict of Interest Disclosures}

Ali Ayoubian serves as a executive manager of International Journal of Travel Medicine and Global Health. SA and CHC declare that they have no conflicts of interest.

\section{Ethical Approval}

Our secondary analysis was found by the Charles R Drew University of Medicine and Science (CDU) Institutional Review Board (IRB) to be exempt from a full IRB review. However, the original ABCD study underwent an Institutional Review Board (IRB) in several institutions, including but not limited to the University of California, San Diego (UCSD). The IRB in multiple institutions approved the study protocol, and all children provided assent and parents signed consent.

\section{Funding/Support}

Assari is supported by the NIH grants CA201415-02, U54CA229974， 5S21MD000103， 54MD008149, R25 MD007610, 2U54MD007598, 4P60MD006923, and U54 TR001627.

\section{ABCD Acknowledgments}

We thank the Adolescent Brain Cognitive Development (ABCD) participants and their families for their time and dedication to this project. Data used in the preparation of this article were obtained from the ABCD Study (https://abcdstudy.org/) and are held in the NIMH Data Archive. This is a multisite, longitudinal study designed to recruit more than 10000 children aged 9-10 and follow them over 10 years into early adulthood. The ABCD study is supported by the National Institutes of Health (NIH) and additional federal partners under award numbers U01DA041022, U01DA041028, U01DA041048, U01DA041089, U01DA041106, U01DA041117, U01DA041120, U01DA041134, U01DA041148, U01DA041156, U01DA041174, U24DA041123 and U24DA041147. A full list of supporters is available at https:// abcdstudy.org/federal-partners/. A listing of participating sites and a complete listing of the study investigators can be found at https://abcdstudy.org/principal-investigators/. ABCD consortium investigators designed and implemented the study

\section{Research Highlights}

What Is Already Known?

High socioeconomic status (SES) is shown to be associated with lower levels of perceived discrimination.

\section{What This Study Adds?}

While high household income is associated with lower levels of perceived discrimination among American children overall, this association is weaker for African American adolescents. Consequently, African American children from middle-class families may experience worsethan-expected health outcomes.

and/or provided data but did not necessarily participate in analysis or writing of this report. This manuscript reflects the views of the authors and may not reflect the opinions or views of the $\mathrm{NIH}$ or $\mathrm{ABCD}$ consortium investigators. The ABCD data repository grows and changes over time. The current paper used the Curated Annual Release 2.0, also defined in NDA Study 634 (doi:10.15154/1503209).

\section{DEAP Funding}

DEAP is a software provided by the Data Analysis and Informatics Center of ABCD located at the UC San Diego with generous support from the National Institutes of Health and the Centers for Disease Control and Prevention under award number U24DA041123. The DEAP project information and links to its source code are available under the resource identifier RRID: SCR_016158.

\section{Supplementary Materials}

Supplementary file 1 contains Table S1 and Figure S1.

\section{References}

1. Phelan JC, Link BG, Tehranifar P. Social conditions as fundamental causes of health inequalities: theory, evidence, and policy implications. J Health Soc Behav. 2010;51 Suppl:S28-40. doi:10.1177/0022146510383498.

2. Farmer MM, Ferraro KF. Are racial disparities in health conditional on socioeconomic status? Soc Sci Med. 2005;60(1):191-204. doi:10.1016/j.socscimed.2004.04.026.

3. Hudson D, Sacks TA, Sewell W, Holland D, Gordon J. Surviving the white space: perspectives on how middle-class Black men navigate cultural racism. Ethnic and Racial Studies. 2020:1-9. doi: 10.1080/01419870.2020.1834594.

4. Assari S. Health disparities due to diminished return among Black Americans: public policy solutions. Soc Issues Policy Rev. 2018;12(1):112-145. doi:10.1111/sipr.12042.

5. Assari S, Caldwell $\mathrm{CH}$. High risk of depression in high-income African American boys. J Racial Ethn Health Disparities. 2018;5(4):808-819. doi:10.1007/s40615-017-0426-1 .

6. Oliver M, Shapiro TM. Black Wealth/White Wealth: A New Perspective on Racial Inequality. Routledge; 2013.

7. Hamilton D, Darity W Jr. Race, wealth, and Intergenerational poverty: there will never be a post-racial America if the wealth gap persists. Am Prospect. 2009;20(7):A10-2.

8. Shapiro TM. The Hidden Cost of Being African American: How Wealth Perpetuates Inequality. USA: Oxford University Press; 2004. 
9. Assari S, Moghani Lankarani M, Caldwell CH. Does discrimination explain high risk of depression among high-income African American men? Behav Sci (Basel). 2018;8(4). doi:10.3390/ bs 8040040 .

10. Pascoe EA, Smart Richman L. Perceived discrimination and health: a meta-analytic review. Psychol Bull. 2009;135(4):531-554. doi:10.1037/a0016059.

11. Mays VM, Cochran SD, Barnes NW. Race, race-based discrimination, and health outcomes among African Americans. Annu Rev Psychol. 2007;58:201-225. doi:10.1146/annurev. psych.57.102904.190212.

12. Assari S, Moghani Lankarani M. Workplace racial composition explains high perceived discrimination of high socioeconomic status African American men. Brain Sci. 2018;8(8). doi:10.3390/ brainsci8080139.

13. Colen CG, Ramey DM, Cooksey EC, Williams DR. Racial disparities in health among nonpoor African Americans and Hispanics: the role of acute and chronic discrimination. Soc Sci Med. 2018;199:167-180. doi:10.1016/j.socscimed.2017.04.051.

14. Hudson DL, Puterman E, Bibbins-Domingo K, Matthews KA, Adler NE. Race, life course socioeconomic position, racial discrimination, depressive symptoms and self-rated health. Soc Sci Med. 2013;97:7-14. doi:10.1016/j.socscimed.2013.07.031.

15. Fuller-Rowell TE, Curtis DS, Chae DH, Ryff CD. Longitudinal health consequences of socioeconomic disadvantage: examining perceived discrimination as a mediator. Health Psychol. 2018;37(5):491-500. doi:10.1037/hea0000616.

16. Assari S. Interaction between race and gender on implicit racial bias against Blacks. Int J Epidemiol Res. 2018;5(2):43-49. doi:10.15171/ijer.2018.10.

17. Assari S, Lapeyrouse LM, Neighbors HW. Income and selfrated mental health: diminished returns for high income Black Americans. Behav Sci (Basel). 2018;8(5). doi:10.3390/bs8050050.

18. Assari S. Race, intergenerational social mobility and stressful life events. Behav Sci (Basel). 2018;8(10). doi:10.3390/bs8100086.

19. Hammond WP. Taking it like a man: masculine role norms as moderators of the racial discrimination-depressive symptoms association among African American men. Am J Public Health. 2012;102(Suppl 2):S232-241. doi:10.2105/ajph.2011.300485.

20. Sidanius J, Pratto F. Social Dominance: An Intergroup Theory of Social Hierarchy and Oppression. New York: Cambridge University Press; 1999.

21. Zajacova A, Rogers RG, Johnson-Lawrence V. Glitch in the gradient: additional education does not uniformly equal better health. Soc Sci Med. 2012;75(11):2007-2012. doi:10.1016/j. socscimed.2012.07.036.

22. Pearson JA. Can't buy me whiteness: new lessons from the Titanic on race, ethnicity, and health. Du Bois Rev. 2008,5(1):27-47. doi:10.10170s1742058x0808003x.

23. Williams DR, Sternthal M. Understanding racial-ethnic disparities in health: sociological contributions. J Health Soc Behav. 2010;51 Suppl:S15-27. doi:10.1177/0022146510383838.

24. Navarro V. Race or class, or race and class. Int J Health Serv. 1989; 19(2):311-314.doi:10.2190/cnuh-67t0-rlbt-fmca.

25. Wilson KB, Thorpe RJ Jr, LaVeist TA. Dollar for Dollar: Racial and ethnic inequalities in health and health-related outcomes among persons with very high income. Prev Med. 2017;96:149-153. doi:10.1016/j.ypmed.2016.08.038.

26. Carbado DW, Crenshaw KW, Mays VM, Tomlinson B. Intersectionality: mapping the movements of a theory. Du Bois Rev. 2013;10(2):303-312. doi:10.1017/s1742058x13000349.

27. Mays VM, Ghavami N. History, aspirations, and transformations of intersectionality: focusing on gender. In: Travis CB, White JW, Rutherford A, Williams WS, Cook SL, Wyche KF, eds. APA Handbooks in Psychology. APA Handbook of the
Psychology of Women: History, Theory, And Battlegrounds. American Psychological Association; 2018. p. 541-566. doi:10.1037/0000059-028.

28. Shelton JE. A dream deferred?: privileged Blacks' and Whites' beliefs about racial inequality. Du Bois Rev. 2017;14(1):73-91. doi:10.1017/s1742058×16000370.

29. Hughes L. Montage of a Dream Deferred. New York: Holt; 1951.

30. Assari S, Mistry R, Lee DB, Caldwell CH, Zimmerman MA. Perceived racial discrimination and marijuana use a decade later; gender differences among Black youth. Front Pediatr. 2019;7:78. doi:10.3389/fped.2019.00078.

31. Assari S, Moazen-Zadeh E, Caldwell CH, Zimmerman MA. Racial discrimination during adolescence predicts mental health deterioration in adulthood: gender differences among Blacks. Front Public Health. 2017;5:104. doi:10.3389/fpubh.2017.00104.

32. Assari S, Caldwell CH. Social determinants of perceived discrimination among Black youth: intersection of ethnicity and gender. Children (Basel). 2018;5(2). doi:10.3390/children5020024.

33. Assari $\mathrm{S}$, Caldwell $\mathrm{CH}$. Darker skin tone increases perceived discrimination among male but not female Caribbean Black youth. Children (Basel). 2017;4(12). doi:10.3390/children4120107.

34. Assari S, Moghani Lankarani M, Caldwell CH. Discrimination increases suicidal ideation in Black adolescents regardless of ethnicity and gender. Behav Sci (Basel). 2017;7(4). doi:10.3390/ bs7040075.

35. Assari S, Boyce S, Bazargan M. Subjective socioeconomic status and children's amygdala volume: Minorities' diminish returns. NeuroSci. 2020;1(2):59-74. doi:10.3390/neurosci1020006.

36. Assari S, Moghani Lankarani M. Workplace racial composition explains high perceived discrimination of high socioeconomic status African American men. Brain Sci. 2018;8(8). doi:10.3390/ brainsci8080139.

37. Assari S. Does school racial composition explain why high income Black youth perceive more discrimination? a gender analysis. Brain Sci. 2018;8(8). doi:10.3390/brainsci8080140.

38. Assari S, Islam S, Diminished Protective Effects of Household Income on Internalizing Symptoms among African American than European American Pre-Adolescents. J Econ Trade Mark Manag. 2020;2(4):38-56. doi:10.22158/jetmm.v2n4p38.

39. Krieger N. Racial and gender discrimination: risk factors for high blood pressure? Soc Sci Med. 1990;30(12):1273-1281.

40. Hudson DL, Bullard KM, Neighbors HW, Geronimus AT, Yang J, Jackson JS. Are benefits conferred with greater socioeconomic position undermined by racial discrimination among African American men?. J Mens Health. 2012;9(2):127-36. doi:10.1016/j. jomh.2012.03.006.

41. Assari S. Social epidemiology of perceived discrimination in the United States: role of race, educational attainment, and income. Int J Epidemiol Res. 2020;7(3):136-141. doi:10.34172/ijer.2020.24.

42. Assari S, Boyce S, Bazargan M. Subjective family socioeconomic status and adolescents' attention: Blacks' diminished returns. Children (Basel). 2020;7(8). doi:10.3390/children7080080.

43. Assari S. Parental education on youth inhibitory control in the Adolescent Brain Cognitive Development (ABCD) study: Blacks' diminished returns. Brain Sci. 2020;10(5). doi:10.3390/ brainsci10050312.

44. Assari S, Boyce S, Akhlaghipour G, Bazargan M, Caldwell $\mathrm{CH}$. Reward responsiveness in the Adolescent Brain Cognitive Development (ABCD) study: African Americans' diminished returns of parental education. Brain Sci. 2020;10(6). doi:10.3390/ brainsci10060391.

45. Assari S. Youth social, emotional, and behavioral problems in the ABCD study: minorities' diminished returns of family income. J Econ Public Financ. 2020;6(4):1-19. doi:10.22158/jepf.v6n4p1. 46. Assari S, Boyce S, Bazargan M. Subjective socioeconomic status 
and children's amygdala volume: minorities' diminish returns. NeuroSci. 2020;1(2):59-74. doi:10.3390/neurosci1020006.

47. Assari S, Akhlaghipour G, Boyce S, Bazargan M, Caldwell CH. African American children's diminished returns of subjective family socioeconomic status on fun seeking. Children (Basel). 2020;7(7). doi:10.3390/children7070075.

48. Assari S, Boyce S, Bazargan M, Caldwell CH. African Americans' diminished returns of parental education on adolescents' depression and suicide in the Adolescent Brain Cognitive Development (ABCD) study. Eur J Investig Health Psychol Educ. 2020;10(2):656-668. doi:10.3390/ejihpe10020048.

49. Assari S, BoyceS, Caldwell CH, Bazargan M. Minorities' diminished returns of parental educational attainment on adolescents' social, emotional, and behavioral problems. Children (Basel). 2020;7(5). doi:10.3390/children7050049.

50. Assari S, Boyce S, Akhlaghipour G, Bazargan M, Caldwell $\mathrm{CH}$. Reward responsiveness in the Adolescent Brain Cognitive
Development (ABCD) study: African Americans' diminished returns of parental education. Brain Sci. 2020;10(6). doi:10.3390/ brainsci10060391.

51. Hutchinson DL. Identity crisis: intersectionality, multidimensionality, and the development of an adequate theory of subordination. Mich J Race Law. 2000;6:285-317.

52. Chetty R, Hendren N, Jones MR, Porter SR. Race and Economic Opportunity in the United States: An Intergenerational Perspective (No. w24441). Cambridge, MA: National Bureau of Economic Research; 2018.

53. Assari S. Educational attainment better protects African American women than African American men against depressive symptoms and psychological distress. Brain Sci. 2018;8(10). doi:10.3390/ brainsci8100182.

54. Assari S. Social Epidemiology of Perceived Discrimination in the United States: Role of Race, Educational Attainment, and Income. Int J Epidemiol Res. 2020;7(3):136. 